\title{
NEOCONSTITUCIONALISMO, DIREITOS FUNDAMENTAIS E CONTROLE DAS POLÍTICAS PÚBLICAS
}

\author{
Ana Paula de Barcellos*
}

\begin{abstract}
Sumário. l. Neoconstitucionalismo: algumas notas; II. Neoconstitucionalismo, direitos fundamentais, Poder Público e políticas públicas; III. Construindo dogmaticamente o controle das políticas públicas; III.1. Identificação dos parâmetros de controle; III.2. Garantia de acesso à informação; III.3. Elaboração de instrumentos de controle; IV. Conclusões.
\end{abstract}

\section{Neoconstitucionalismo: algumas notas}

A expressão "neoconstitucionalismo" tem sido utilizada por parte da doutrina para designar o estado do constitucionalismo contemporâneo'. O prefixo neo parece transmitir a idéia de que se está diante de um fenômeno novo, como se o constitucionalismo atual fosse substancialmente diverso daquilo que o antecedeu. De fato, é possível visualizar elementos particulares que justificam a sensação geral compartilhada pela doutrina de que algo diverso se desenvolve diante de nossos olhos e, nesse sentido, não seria incorreto falar de um novo período ou momento no direito constitucional. Nada obstante isso, fenômeno humano e histórico que é, o constitu-

* Mestre e Doutora em Direito Público pela Faculdade de Direito da UERJ. Professora Adjunta de Direito Constitucional da Faculdade de Direito da UERJ. Advogada no Rio de Janeiro.

I SANCHÍS, Luis Prieto. "Neoconstitucionalismo y ponderación judicial". In: CARBONELL, Miguel (org.). Neoconstitucionalimo(s), 2003; ARIZA, Santiago Sastre. "La ciencia jurídica ante el neoconstitucionalismo". In: CARBONELL, Miguel (org.). Neoconstitucionalismo(s), 2003; BARBERIS, Mauro, "Neoconstitucionalismo, democracia e imperialismo de la moral". In: CARBONELL, Miguel (org.). Neoconstitucionalismo(s), 2003; e COMANDUCCI, Paolo. "Formas de (neo)constitucionalismo: un análisis metateórico". In: CARBONELL, Miguel (org.). Neoconstitucionalismo(s), 2003. 
cionalismo contemporâneo está ligado de forma indissociável a sua própria história² 2 como se verá adiante.

É possível ordenar as características específicas mais destacadas do chamado neoconstitucionalismo em dois grupos principais, por simplicidade: um que congrega elementos metodológico-formais e outro que reúne elementos materiais. Seguem algumas notas sobre cada um deles.

Do ponto de vista metodológico-formal, o constitucionalismo atual opera sobre três premissas fundamentais, das quais depende em boa parte a compreensão dos sistemas jurídicos ocidentais contemporâneos. São elas: (i) a normatividade da Constituição, isto é, o reconhecimento de que as disposições constitucionais são normas jurídicas, dotadas, como as demais, de imperatividade ${ }^{3}$; (ii) a superioridade da Constituição sobre o restante da ordem jurídica (cuida-se aqui de Constituições rígidas, portanto ${ }^{4}$ ); e (iii) a centralidade da Carta nos sistemas jurídicos, por força do fato de que os demais ramos do Direito devem ser compreendidos e interpretados a partir do que dispõe a Constituição ${ }^{5}$. Essas três características são herdeiras do processo histórico que levou a Constituição de documento essencialmente político, e dotado de baixíssima imperatividade, à norma jurídica suprema, com todos os corolários técnicos que essa expressão carrega ${ }^{6}$.

A particularidade do neoconstitucionalismo consiste em que. consolidadas essas três premissas na esfera teórica, cabe agora concretizá-las, elaborando técnicas jurídicas que possam ser utilizadas no dia-a-dia da aplicação do direito. O neoconstitucionalismo vive essa passagem, do teórico ao concreto, de feérica, instável e em

2 ORTEGA Y GASSET, José. Que é filosofia?, 1971, p. 1 l e ss.; e SALDANHA, Nelson. Filosofia do direito, 1998, p. 2: “ (...) as transformações históricas afetam tanto as perguntas como as respostas (...)".

3 O elemento essencial do direito, e da norma jurídica em particular, consiste na imperatividade dos efeitos propostos. Trata-se da capacidade de impor pela força, se necessário, a realização dos efeitos pretendidos pela norma ou de algum tipo de conseqüência ao descumprimento desta, capaz de provocar, mesmo que substitutivamente, a realização do efeito normativo inicialmente previsto ou um seu equivalente. Sobre o tema, v. ENGISH, Karl. Introdução ao pensamento juridico, 1983. p. 27 e ss.; BOBBIO, Norberto. Teoria do ordenamento juridico, 1997, pp. 21 : 22; ¿ LARENZ. Karl. Metodologia da ciência do direito, 1969, p. 214.

4 Uma Constituição é considerada rígida quando sua reforma depende de um processo legislativo mais complexo do que o exigido para a edição de leis infraconstitucionais. Este é, naturalmente. um conceito formal. Muitas vezes, Constituições não rígidas (flexiveis) podem ser substancialmente mais estáveis, no tempo, que as rígidas. É o que se passa, como se sabe, na experiência inglesa.

5 BARROSO, Luís Roberto. "Fundamentos teóricos e filosóficos do novo direito constitucional brasileiro (pós-modernidade, teoria crítica e pós-positivismo)". In: BARROSO. Luís Roberto (org.). A nova interpretação constitucional. Ponderação, direitos fundamentais e relaçōes privadas, 2003, pp. 1 a 49; e ANDRADE, André. A constitucionalização do direito: a Constituição como lócus da hermenêutica juridica, 2003.

6 Sobre o processo histórico que conduziu a Constituição de documento puramente político a documento jurídico, vejam-se Eduardo Garcia de Enterria, La Constitacion como norma y al Tribunal Constitucional, 1985; e Konrad Hesse, A força normativa da Constituição, 1991. 
muitas ocasiões inacabada construção de instrumentos por meio dos quais se poderá transformar os ideais da normatividade, superioridade e centralidade da Constituição em técnica dogmaticamente consistente e utilizável na prática jurídica.

Nesse contexto se inserem, por exemplo, as discussões sobre a eficácia jurídica . dos princípios constitucionais ${ }^{7}$, as possibilidades de controle das omissões inconstitucionais e os diversos estudos que procuram compreender e interpretar a legislação ordinária a partir do texto constitucional, como acontece de forma especialmente marcante com o direito civil, o direito penal e o direito processual ${ }^{8}$. Como se verá, o tema do controle das políticas públicas - objeto central deste pequeno estudo está inserido nesse mesmo esforço de concretização técnica das noções de normatividade, superioridade e centralidade da Constituição.

Do ponto de vista material, ao menos dois elementos caracterizam o neoconstitucionalismo e merecem nota: (i) a incorporação explícita de valores e opções políticas nos textos constitucionais, sobretudo no que diz respeito à promoção da dignidade humana e dos direitos fundamentais; e (ii) a expansão de conflitos específicos e gerais entre as opções normativas e filosóficas existentes dentro do próprio sistema constitucional. Explica-se melhor.

As Constituições contemporâneas, sobretudo após a Segunda Guerra Mundial, introduziram de forma explícita em seus textos elementos normativos diretamente vinculados a valores - associados, em particular, à dignidade humana e aos direitos fundamentais $^{9}$ - ou a opções políticas, gerais (como a redução das desigualdades sociais ${ }^{10}$ ) e específicas (como a prestação, pelo Estado, de serviços de educação ${ }^{11}$ ). $\mathrm{A}$ introdução desses elementos pode ser compreendida no contexto de uma reação

7 Sobre o tema, apenas exemplificativamente, v. PEIXINHO, Manoel Messias. Os princípios da Constituição de 1988, 2001; BARCELLOS, Ana Paula de. A eficácia jurídica dos princípios constitucionais: O principio da dignidade da pessoa humana, 2002, p. 40 e ss.; e SANCHIS. Luis Prieto. Sobre principios y normas. Problemas del razonamiento juridico, 1992.

8 V. exemplificativamente, GOUVÊA, Marcos Maselli. O controle judicial das omissōes administrativas, 2003; PIOVESAN, Flavia. Proteção judicial contra omissões legislativas, 2003; GOMES, Luís Roberto. Ministério Público e o controle da omissão administrativa. 2003: TEPEDINO. Gustavo. A parte geral do novo Código Civil: Estudos na perspectiva civil-constitucional. 2003: TEPEDINO, Gustavo. Problemas de direito civil constitucional, 2000; MORAES, Maria Celina Bodin de. Danos à pessoa humana: Uma leitura civil-constitucional dos danos morais, 2003; PERLINGIERI, Pietro. Perfis do direito civil; introdução ao direito civil constitucional, 2002.: e PRADO, Luís Regis. Bem jurídico-penal e Constituição, 2003: PASCHOAL. Janaina Conceição. Constituição, criminalização e direito penal mínimo, 2003; e MEDINA. Paulo Roberı de Gouvêa. Direito processual constitucional. 2003.

9 Diversos países cuidaram de introduzir em suas Constituições a dignidade da pessoa humana como fundamento do Estado que se criava ou recriava, juridicizando. com estatura constitucional, o tema. É o caso, e.g., das Constituições alemã, espanhola e portuguesa. Na França, a dignidade humana é considerada um elemento implícito desde a Declaração de 1789. Constituiçōes mais recentes, como a da África do Sul, também consagram dispositivo nessa linha.

$10 \mathrm{CF} / 88$, art. $3^{\circ}$, III.

$11 \mathrm{CF} / 88$, arts. 23, V, e 205. 
mais ampla a regimes políticos que, ao longo do Século $\mathrm{XX}$, substituíram os ideais iluministas de liberdade e igualdade pela barbárie pura e simples, como ocorreu com o nazismo e o fascismo. Mesmo onde não se chegou tão longe. regimes autoritários. opressão política e violação reiterada dos direitos fundamentais foram as marcas de muitos regimes políticos ao longo do século passado ${ }^{12}$.

Com a superação desses regimes, diversos países decidiram introduzir em seus textos constitucionais elementos relacionados a valores e a opções políticas fundamentais, na esperança de que eles formassem um consenso mínimo a ser observado pelas maiorias. Essa esperança era reforçada - e continua a ser - pelo fato de tais elementos gozarem do status de norma jurídica dotada de superioridade hierárquica sobre as demais iniciativas do Poder Público. Por esse mecanismo. então, o consenso mínimo a que se acaba de referir passa a estar fora da discricionariedade da política ordinária, de tal modo que qualquer grupo político deve estar a ele vinculado ${ }^{3}$.

Essa primeira característica material se liga de forma direta à questão metodológica a que se fez menção acima. Com efeito, a partir do momento em que valores e opções políticas transformaram-se em normas jurídicas, tornou-se indispensável desenvolver uma dogmática específica capaz de conferir eficácia jurídica a tais elementos normativos. Esse é. sem dúvida, um dos desafios do neoconstitucionalismo.

A segunda característica de natureza material referida acima envolve a questão dos conflitos. No direito constitucional contemporâneo, tanto sob a perspectiva da teoria jurídica, como da experiência observada nos juízos e tribunais, é possível falar de conflitos específicos e de um conflito geral.

Os conflitos específicos se explicam, em boa medida, pelo reflexo, nos textos constitucionais, de diferentes pretensões, que necessitam conviver e harmonizar-se ${ }^{14}$

12 BARCELLOS, Ana Paula de. A eficácia jurídica dos princípios constitucionais: O princípio da dignidade da pessoa humana, 2001: "Infelizmente, uma infinidade de exemplos pode ser arrolada neste ponto: Biafra, na Nigéria dos anos 60, o Khmer Vermelho no Camboja, os conflitos étnicos em Rhuanda, Uganda. Bósnia e Kosovo, as ditaduras na China e no Tibet. em Cuba e na América Latina. a fome e a miséria endêmica na Etiópia e diversos outros países africanos, a pobreza crônica, o analfabetismo e os regimes de semi-escravidão e exploração do trabalho infantil na América Latina é Ásia elc.". Alguns desses fatos sào analisados por HOBSBAWN. Eric. Era dos extremos - O breve século XX, 1999.

13 É certo que a dignidade é uma característica inerente ao homem, que a norma apenas reconhece; daí por que muitos autores registram que não há um 'direito' à dignidade e sim o direito ao respeito à dignidade e à sua promoção. A importância dessa observação está em que o indivíduo continua sendo digno nada obstante a violação das normas que pretendem assegurar condições de dignidade. Nessas hipóteses, a pessoa estará sendo submetida à uma situação indigna. incompatível com sua dignidade essencial. V. SARLET, Ingo Wolfgang. Dignidade da pessoa humana e direitos fundamentais, 2001, p. 49 e ss..

14 CANOTILHO, J. J. Gomes. Direito constitucional e teoria da Constituição, 1998, p. 21 1-2: "Numa sociedade plural e complexa a constituição é sempre um produto de um 'pacto' entre forças políticas e sociais. Através da 'barganha' e de 'argumentação', de 'convergência' e diferenças, de cooperação na deliberação mesmo em caso de desacordos persistentes, foi possível chegar, no procedimento constituinte, a um compromisso constitucional ou, se preferirmos, a vários "compromissos constitucionais"." 
em uma sociedade plural como a contemporânea. Sua configuração envolve, freqüentemente, colisões, reais ou aparentes, entre diferentes comandos constitucionais, dotados de igual hierarquia, cada qual incidindo sobre determinada situação de fato e postulando uma solução jurídica diversa ${ }^{15}$. Assim. direitos fundamentais - elementos centrais dos sistemas constitucionais contemporâneos - parecem entrar em choque em muitas circunstâncias. Outros elementos constitucionais também podem apresentar uma convivência difícil em determinados ambientes, como acontece, e.g., com a livre iniciativa e os princípios da proteção ao consumidor e ao meio-ambiente. O exemplo já clássico da tensão entre liberdade de informação e de expressão e intimidade, honra e vida privada é apenas um entre muitos outros que poderiam ser citados $^{16}$.

Além dos conflitos específicos, o neoconstitucionalismo convive ainda com um conflito de caráter geral, que diz respeito ao próprio papel da Constituição. Trata-se da oposição entre duas idéias diversas acerca desse ponto. A primeira delas sustenta

15 Os autores sugerem diferentes formas e técnicas na tentativa de solucionar essas colisões. Sobre o tema, v. ALEXY, Robert. Sistema jurídico, principios juridicos y razón práctica, Revista Doxa $\mathrm{n}^{\circ} 5.1988$, pp. 149 e ss..; SCACCIA. Gino. Il bilanciamento degli interessi come tecnica di controllo costituzionale, Giurisprudenza constituzionale, vol. VI, 1998, p. 3962 e ss.; SERNA. Pedro e TOLLER, Fernando. La interpretación constitucional de los derechos fundamentales. Una alternativa a los conflictos de derechos, 2000; STEINMETZ, Wilson Antônio. Colisão de direitos fundamentais e princípio da proporcionalidade, 2001; BARCELLOS, Ana Paula de. Ponderação, racionalidade e atividade jurisdicional, 2005 (no prelo).

16 Há ampla bibliografia sobre o tema. V., por todos, CALDAS, Pedro Frederico. Vida privada, liberdade de imprensa e dano moral, 1997: Edilsom Pereira de. Colisão de direitos fundamentais. A honra, a intimidade, a vida privada e a imagem versus a liberdade de expressão e de informação, 2000; e BARROSO, Luis Roberto. Colisão entre liberdade de expressão e direitos da personalidade. Critérios de ponderação. Interpretação constitucionalmente adequada do Código Civil e da Lei de Imprensa, Revista de Direito Administrativo n 235, 2004, pp. I a 36. Recentemente, a Corte Européia de Direitos Humanos proferiu importante decisão declarando contrária ao art. $8^{\circ}$ da Convenção Européia de Direitos Humanos a orientação do Tribunal Constitucional Federal alemão em matéria de proteção à privacidade de figuras públicas. A questão foi levada à Corte Européia pela princesa Caroline von Hannover, do Principado de Mônaco, após diversas tentativas de impedir a publicação de fotos suas em atividades cotidianas (e.g., fazendo compras ou praticando esportes). A Corte Européia considerou que os critérios do Tribunal alemão não protegiam satistatoriamente a privacidade e defendeu a necessidade de uma ponderação orientada pelo seguinte critério: a publicação se justificaria na medida em que trouxesse uma contribuição para o "debate de interesse geral", para além da satisfação de uma mera curiosidade do público. Os eventos da vida cotidiana de uma pessoa pública, a princípio, não poderiam ser objeto de divulgação. ainda quando ocorridos em ambientes que não possam ser considerados como "reservados". Dois juízes da Corte. embora endossando o resultado do julgamento, discordaram do critério fixado, retomando em parte o argumento do Tribunal alemão no sentido de que também há um interesse juridicamente tutelável ao "entretenimento". O critério, para tais juízes, deveria ser a existência ou não de uma "expectativa legítima de privacidade", que não estaria presente quando uma figura pública vai às compras, mas estaria quando pratica esportes em um ambiente aparentemente protegido de observação externa. A íntegra da decisão pode ser obtida no site da Corte Européia de Direitos Humanos (http://www.echr.coe.int). 
que cabe à Constituição impor ao cenário político um conjunto de decisões valorativas que se consideram essenciais e consensuais. Essa primeira concepção pode ser descrita, por simplicidade, como substancialista. Um grupo importante de autores, no entanto, sustenta que apenas cabe à Constituição garantir o funcionamento adequado do sistema de participação dẹmocrático, ficando a cargo da maioria, em cada momento histórico, a definição de seus valores e de suas opções políticas. Nenhuma geração poderia impor à seguinte suas próprias convicções materiais. Esta segunda forma de visualizar a Constituição pode ser designada de procedimentalismo ${ }^{17}$.

É bem de ver que o conflito substancialismo versus procedimentalismo não opõe realmente duas idéias antagônicas ou totalmente inconciliáveis. O procedimentalismo, em suas diferentes vertentes, reconhece que o funcionamento do sistema de deliberação democrática exige a observância de determinadas condições, que podem ser descritas como opções materiais e se reconduzem a opções valorativas ou políticas. Com efeito. não haverá deliberação majoritária minimamente consciente e consistente sem respeito aos direitos fundamentais dos participantes do processo deliberativo, o que inclui a garantia das liberdades individuais e de determinadas condições materiais indispensáveis ao exercício da cidadania ${ }^{18}$. Em outras palavras. o sistema de diálogo democrático não tem como funcionar de forma minimamente adequada se as pessoas não tiverem condições de dignidade ou se seus direitos, ao menos em patamares mínimos, não forem respeitados.

17 V. sobre o tema do "substancialismo versus procedimentalismo", ELY. John Hart. Democracy and distrust. A theory of judicial review, 1980; VIEIRA. Oscar Vilhena. A Constituição e sua reserva de justiça, 1999, p. 213 e ss.; BINENBOJM, Gustavo. A nova jurisdição constitucional brasileira. 2001, p. 93 e ss.: PIRES, Francisco Lucas. "Legitimidade da justiça constitucional e princípio da maioria". In: Legitimidade e legitimação da justiça constituc iomal - Colriquio no $10^{\circ}$ aniversário do Tribunal Constitucional, 1995, p. 167 e ss.; e HAGE SOBRINHO, Jorge. "Democracy and distrust - A Theory of judicial review" - John Hart Ely: resumo e breves anotaçós à luz da doutrina contemporânea sobre interpretaçāo constitucional, Arquivos do Ministério da Justiça n 48 (186), 1995, pp. 201 a 225; e SOUZA NETO, Cláudio Pereira de. Teoria constitucional e democracia deliberativa, 2005 (no prelo).

is $\mathrm{Na}$ verdade, as diferentes teorias que incorporam elementos procedimentais assumem como pressuposto a igualdade de todos os indivíduos e, a fortiori. uma primeira característica legitimadora dos diferentes modelos procedimentais por eles propostos deverá ser seu caráter democrático. A consequiência direta desses pressupostos - a igualdade e o caráter democrático do procedimento - é a necessidade de assegurar a liberdade das pessoas para que elas possam participar do procedimento. E. para que essa liberdade possa ser exercida em condições razoáveis. exige-se também um conjunto mínimo de condições materiais, como educação, alimentação. etc.. $V$. HABERMAS, Jurgen. Direito e democracia entre facticidade e validade, vol. I, 2003, p. 154 e ss.: BAYÓN, Juan Carlos. “Derechos, Democracia y Constitución”. In: CARBONELL, Miguel (org.). Neoconstitucionalismo(s), 2003, p. 225 e ss.; MAIA, Antônio Cavalcanti. "Direitos humanos e a teoria do discurso do direito e da democracia". In: TORRES, Ricardo Lobo e MELLO, Celso Albuquerque (organizadores). Arquivos de direitos humanos, vol. II, 2000, p. 58 e ss.; e NASCIMENTO, Rogério Soares do. "A Ética do discurso como justificação dos direitos fundamentais na obra de Jürgen Habermas”. In: TORRES, Ricardo Lobo (org.). Legitimação dos direitos humanos, pp. 451 a $498,2002$. 
Esse conflito, longe de ser apenas um debate de interesse acadêmico, afeta a concepção do aplicador do direito acerca do sentido e da extensão do texto constitucional que lhe cabe interpretar e, a fortiori, repercute sobre a interpretação jurídica como um todo. É fácil perceber que uma visão fortemente substancialista tenderá a justificar um controle de constitucionalidade mais rigoroso e abrangente dos atos e normas produzidos no âmbito do Estado, ao passo que uma percepção procedimentalista conduz a uma postura mais deferente acerca das decisões dos Poderes Públicos.

\section{Neoconstitucionalismo, direitos fundamentais, Poder Público e políticas públicas}

No tópico anterior apresentou-se uma rápida visão das características centrais do constitucionalismo contemporâneo ou, como muitos preferem designar, neoconstitucionalismo. Como se referiu acima, um dos traços fundamentais do constitucionalismo atual é a normatividade das disposições constitucionais, sua superioridade hierárquica e centralidade no sistema e, do ponto de vista material, a incorporação de valores e opções políticas, dentre as quais se destacam, em primeiro plano, aquelas relacionadas com os direitos fundamentais. Os conflitos próprios do constitucionalismo contemporâneo ocorrem freqüentemente entre direitos fundamentais justamente porque não é possível hierarquizá-los em abstrato, dada a sua fundamentalidade ${ }^{19}$. Ainda sob a ótica dos conflitos, substancialistas e procedimentalistas concordam, por razões diversas, que os direitos fundamentais formam um consenso mínimo oponível a qualquer grupo político, seja porque constituem elementos valorativos essenciais, seja porque descrevem exigências indispensáveis para o funcionamento adequado de um procedimento de deliberação democrática.

Em suma: a Constituição é norma jurídica central no sistema e vincula a todos dentro do Estado, sobretudo os Poderes Públicos. E, de todas as normas constitucionais, os direitos fundamentais integram um núcleo normativo que, por variadas razões, deve ser especificamente prestigiado. O que se acaba de resumir não representa qualquer novidade. Ao contrário, cuidou-se apenas de sistematizar suscintamente dados básicos do conhecimento já consolidado acerca do constitucionalismo contemporâneo. Estabelecidas essas premissas, passa-se à discussão sobre as políticas públicas e seu controle.

Como é amplamente corrente, a promoção e a proteção dos direitos fundamentais exigem omissões e ações estatais. A liberdade de expressão, e.g., será substancialmente protegida na medida em que o Poder Público não procure cerceá-la ou submetê-la de alguma forma. A omissão, nesse caso, será fundamental. Quando se trate de direitos relacionados, e.g., com a aquisição de educação formal, prestações

19 MORESO, José Juan. “Conflictos entre principios constitucionales”. In: CARBONELL. Miguel (org.). Neoconstitucionalismo(s), 2003; e BARCELLOS, Ana Paula de. Ponderação, racionalidade e atividade jurisdicional, 2005 (no prelo). 
de saúde ou condições habitacionais, a situação é bastante diversa, já que a promoção de tais direitos depende de ações por parte do Poder Público. O ponto é demasiado conhecido e não há necessidade de discorrer sobre ele, salvo por um aspecto fundamental: as ações estatais capazes de realizar os direitos fundamentais em questão envolvem, em última análise, decisões acerca do dispêndio de recursos públicos. Aprofunda-se a questão.

As atividades legislativa e jurisdicional envolvem, por natural, a aplicação da Constituição e o cumprimento de suas normas. O legislador cuida de disciplinar os temas mais variados de acordo com os princípios constitucionais. O magistrado, por seu turno, estará sempre aplicando a Constituição, direta ou indiretamente, já que a incidência de qualquer norma jurídica será precedida do exame de sua própria constitucionalidade e deve se dar da maneira que melhor realize os fins constitucionais. Ocorre que as decisões judiciais produzem, como regra, efeitos alpenas pontuais. entre as partes ${ }^{20}$, e a legislação depende de atos de execução para tornar-se realidade.

Nesse contexto, compete à Administração Pública efetivar os comandos gerais contidos na ordem jurídica e, para isso, cabe-lhe implementar ações e programas dos mais diferentes tipos, garantir a prestação de determinados serviços, etc. ${ }^{21}$. Esse conjunto de atividades pode ser identificado como 'políticas públicas'. É fácil perceber que apenas por meio das políticas públicas o Estado poderá, de forma sistemática e abrangente, realizar os fins previstos na Constituição (e muitas vezes detalhados pelo legislador), sobretudo no que diz respeito aos direitos fundamentais que dependam de ações para sua promoção.

Ora, toda e qualquer ação estatal envolve gasto de dinheiro público e os recursos públicos são limitados ${ }^{22}$. Essas são evidências fáticas e não teses jurídicas. A rigor. a simples existência dos órgãos estatais - do Executivo, do Legislativo e do Judiciário - envolve dispêndio permanente, ao menos com a manutenção das instalações físicas e a remuneração dos titulares dos poderes e dos servidores públi$\cos ^{23}$, afora outros custos. As políticas públicas, igualmente, envolvem gastos. Como não há recursos ilimitados, será preciso priorizar e escolher em que o dinheiro público disponível será investido. Essas escolhas, portanto, recebem a influência direta das opções constitucionais acerca dos fins que devem ser perseguidos em caráter prioritário. Ou seja: as escolhas em matéria de gastos públicos não constituem um tema

20 As exceções a essa regra, ainda que em intensidades diversas, se verificam no âmbito da ação civil pública e do controle abstrato de constitucionalidade.

2 V. SEABRA FAGUNDES, M.. O Controle dos atos administrativos pelo Poder Judiciário, 1984, p. 3-5: “A função legislativa liga-se aos fenômenos de formação do Direilo, ao passo que as outras duas prendem-se à fase de sua realização. Legislar consiste em editar o direito positivo. administrar é aplicar a lei de ofício e julgar é aplicar a lei contenciosamente. O exercício dessas funções é distribuído pelos órgãos denominados Poder Legislativo, Poder Executivo e Poder Judiciário, sendo de notar que nenhum deles exerce, de modo exclusivo, a funçāo que nominalmente lhe corresponde."

22 HOLMES, Stephen e SUNSTEIN, Cass R. The cost of rights, 1999.

23 GALDINO, Flávio. O custo dos direitos. In: Ricardo Lobo Torres (org.). Legitimação dos direitos humanos, 2002, p. 139-222. 
integralmente reservado à deliberação política; ao contrário, o ponto recebe importante incidência de normas jurídicas constitucionais.

Visualize-se novamente a relação existente entre os vários elementos que se acaba de expor: (i) a Constituição estabelece como um de seus fins essenciais a promoção dos direitos fundamentais; (ii) as políticas públicas constituem o meio pelo qual os fins constitucionais podem ser realizados de forma sistemática e abrangente; (iii) as políticas públicas envolvem gasto de dinheiro público: (iv) os recursos públicos são limitados e é preciso fazer escolhas; $\operatorname{logo}(v)$ a Constituição vincula as escolhas em matéria de políticas públicas e dispêndio de recursos públicos.

$\mathrm{Na}$ realidade, o conjunto de gastos do Estado é exatamente o momento no qual a realização dos fins constitucionais poderá e deverá ocorrer. Dependendo das escolhas formuladas em concreto pelo Poder Público, a cada ano, esses fins poderão ser mais ou menos atingidos, de forma mais ou menos eficiente. ou poderão mesmo não chegar sequer a avançar minimamente. A questão merece ainda três observações adicionais.

O chamado 'Estado de Direito' significa, de forma propositadamente simples, o Estado no qual o exercício do poder político está submetido a regras jurídicas ${ }^{24}$. Em um Estado de Direito constitucional regido por uma Constituição rígida, essa submissão será ainda mais ampla. Isso porque, mesmo em um Estado de Direito. o poder político poderá, valendo-se dos procedimentos adequados, alterar as regras jurídicas a que está submetido. Essa possibilidade de alteração persiste em face de uma Constituição rígida, embora se exija um procedimento substancialmente mais complexo do que aquele destinado a alterar a legislação ordinária.

Nada obstante, quando a Constituição consagra cláusulas pétreas - que, na Carta de 1988, incluem os direitos fundamentais (CF, art. $60, \S 4^{\circ}$, IV) 一, nada há que o poder político ordinário possa fazer acerca de tais normas, salvo submeter-se. Com efeito, na visão substancialista referida acima, esse conjunto de normas constitucionais imodificáveis constitui justamente um núcleo mínimo de decisões que deve ser observado por qualquer grupo político no poder, sobretudo no que diz respeito aos direitos fundamentais. Mesmo sob a ótica procedimentalista. a promoção de tais direitos é condição prévia indispensável ao funcionamento do processo de deliberação democrático. Se é assim, e examinando a questão em abstrato, da mesma forma como é consistente afirmar que a ação do poder político está submetida à Constituição, não há qualquer óbice teórico à conclusão exposta acima de que uma

24 CANOTILHO, J. J. Gomes. Direito constitucional e teoria da Constituição, 1998, p. 91: "A limitação do Estado pelo direito também teria de estender-se ao próprio soberano: este estava também submetido ao império da lei, transformando-se em "órgão do Estado"; e SILVA, José Afonso da. O Estado democrático de direito, Jurisprudência Mineira n 101. 1988, p. I a 10. V.. nessa linha. STF. DJ 20.mai.1986. RE 1024I3/MG, Rel. Min. Carlos Madeira: "Tal determinação judicial supõe o Estado de Direito, em que o próprio Estado se submete à sua justiça.": eSTJ, DJU 5.fev.2001, RMS 10181/SE, Rel. Min. José Delgado: "O repasse das dotações orçamentárias pelo Poder Executivo, nos termos previstos no art. 168 da Carta Magna de 1988, não pode ficar à mercê da vontade do Chefe do Executivo, sob pena de se por em risco a independência desses poderes, garantia inerente ao Estado de Direito.". 
norma jurídica - a Constituição - interfere em caráter imperativo na definição dos gastos públicos.

O que se acaba de afirmar - e essa é a segunda observação - não significa que não haja espaço autônomo de deliberação majoritária acerca da definição das políticas públicas ou do destino a ser dado aos recursos disponíveis. Muito ao revés. Em um Estado democrático. não se pode pretender que a Constituição invada o espaço da política em uma versão de substancialismo radical e elitista, em que as decisões políticas são transferidas, do povo e de seus representantes, para os reis filósofos da atualidade: os juristas e operadores do direito em geral. A definição dos gastos públicos é, por certo, um momento típico da deliberação político-majoritária: salvo que essa deliberação não estará livre de alguns condicionantes jurídico-constitucionais.

Se a Constituição contém normas nas quais estabeleceu fïns públicos prioritários, e se tais disposições são normas juridicas, dotadas de superioridade hierárquica e de centralidade no sistema, não haveria sentido em concluir que a atividade de definição das políticas públicas - que irá, ou não, realizar esses fins - deve estar totalmente infensa ao controle jurídico. Em suma: não se trata da absorção do político pelo jurídico, mas apenas da limitação do primeiro pelo segundo. E com isto chega-se à última observação a fazer neste ponto.

Em um Estado republicano, os agentes públicos agem por delegação da população como um todo e em seu favor, devendo prestar contas de suas decisões. Embora não se cogite mais do antigo mandato imperativo ${ }^{25}$, é certo que a delegação envolvida na representação política não é absoluta; não se trata de um 'cheque em branco' que admite qualquer tipo de decisão ou conduta por parte do representante. Nesse sentido, a liberdade do titular de um mandato político simplesmente não justifica ou autoriza decisões idiossincráticas, comprovadamente ineficientes ou simplesmente sem sentido. Assim, além da vinculação específica aos fins prioritários contidos no texto constitucional, a definição das políticas públicas e, conseqüentemente, do destino a ser dado aos recursos públicos, sofre uma limitação jurídica genérica que decorre do próprio Estado republicano.

Até aqui se cuidou de apresentar as razões que fundamentam, teoricamente, a possibilidade - e, a rigor, a necessidade - de controle jurídico da definição das políticas públicas em geral e do destino a ser dado aos gastos públicos em particular. Essa, entretanto, não é a questão realmente importante. O ponto vital que se coloca é como transformar essa possibilidade em dogmática jurídica aplicável no dia-a-dia

25 SILVA. José Afonso da. Curso de direito constitucional positiı, 2001, p. 143-4: "O mandato imperativo vigorou antes da Revolução Francesa, de acordo com o qual seu tilular ficava vinculado a seus eleitores, cujas instruções teria que seguir nas assembléias parlamentares: se aí surgisse fato novo, para o qual não dispusesse de instrução, ficaria obrigado a obtê-la dos eleitores, antes de agir; estes poderiam cassar-lhe a representação. Aí o princípio da revogabilidade do mandato imperativo. (...) É livre [o mandato], porque o representante não está vinculado aos seus eleitores, de quem não recebe instrução alguma, e se receber não tem obrigação jurídica de atender, e a quem. por tudo isso, não tem que prestar conta, juridicamente falando, ainda que politicamente o faça, tendo em vista o interesse na reeleição." 
da interpretação jurídica, preservando-se ainda a harmonia com outros elementos constitucionais pertinentes, como a separação de poderes, as regras orçamentárias, a legalidade das despesas públicas etc.. O próximo tópico ocupa-se de lançar algumas idéias preliminares sobre esse tema, com o objetivo e a pretensão de desencadear a discussão necessária à construção dessa dogmática.

\section{Construindo dogmaticamente o controle das políticas públicas}

Para um estudante de direito dos primeiros períodos será curioso comparar a quantidade de títulos jurídicos dedicados ao tema da tributação com aqueles que se ocupam de estudar a questão do gasto dos recursos públicos, recursos esses obtidos pelo Estado, em sua maior parte, pela arrecadação tributária. Ao passo que há grande e contínua produção doutrinária sobre o primeiro tema, sempre da maior relevância, o material específico existente sobre os gastos públicos e suas condicionantes jurídicas é bastante limitado. Há uma grave e legítima preocupação em limitar juridicamente o ímpeto arrecadador do Estado; nada obstante, não existe preocupação equivalente com o que o Estado fará, afinal, com os recursos arrecadados.

É certo que muitos debates que se desenvolvem no âmbito do direito tributário têm origem e são alimentados por um dado da realidade: o impeto arrecadador do Estado. A realidade das despesas públicas, entretanto, deveria despertar interesse semelhante: desperdício e ineficiência, prioridades incompatíveis com a Constituição, precariedade de serviços indispensáveis à promoção de direitos fundamentais básicos, como educação e saúde, e sua convivência com vultosos gastos em rubricas como publicidade governamental e comunicação social não são propriamente fenômenos pontuais e isolados na Administração Pública brasileira.

A construção de uma dogmática jurídica consistente que viabilize o controle jurídico das políticas públicas no Brasil depende do desenvolvimento teórico de ao menos três temas: (i) a identificação dos parâmetros de controle; (ii) a garantia de acesso à informação; e (iii) a elaboração dos instrumentos de controle. Cada um deles merece uma nota específica.

\section{II.l. Identificação dos parâmetros de controle}

A construção de qualquer dogmática que pretenda viabilizar, do ponto de vista técnico-jurídico, o controle das políticas públicas depende, antes de qualquer outra coisa, da identificação dos parâmetros de controle aplicáveis. Com efeito, controlar as decisões do Poder Público nesse particular significará, e.g., concluir que determinada meta constitucional é prioritária e, por isso, a autoridade pública está obrigada a adotar políticas a ela associadas. Significará, também, afirmar que determinada política pública, embora aprovada pelos órgãos majoritários, não deve ser implementada até que as metas prioritariamente estabelecidas pelo constituinte originário tenham sido atingidas. A questão, portanto, é a seguinte: com que fundamento se 
poderá chegar a tais conclusões? Por que determinada política pública pode ser considerada prioritária em relação a outra?

A dificuldade nesse particular consiste justamente em definir quais são esses parâmetros com fundamento nos quais se pretende fazer o controle, uma vez que eles apenas se justificam se puderem ser extraídos de forma consistente do texto constitucional. Registrou-se acima que as decisões do Poder Público acerca da definição de políticas públicas podem - e devem - ser controladas juridicamente, pois toda ação estatal está vinculada à Constituição em geral e a seus fins em particular. Mas quais são esses fins e em que tipo de atuação específica eles se desdobram? O que decorre da Constituição como atividade juridicamente vinculada e o que está na esfera da decisão política?

É certo que os fins constitucionais podem ser descritos como a realização da dignidade humana e a promoção e proteção dos direitos fundamentais. Nada obstante. essa assertiva é excessivamente genérica e produzirá pouca repercussão prática. A questão que realmente importa é a seguinte: a partir das metas gerais de promoção e proteção da dignidade humana e dos direitos fundamentais, o que o Poder Público está efetiva e especificamente obrigado a fazer em caráter prioritário, autorizando assim o controle judicial?

Lembre-se que muitos direitos fundamentais, assim como a própria dignidade humana, são veiculados sob a forma de princípios, que, por sua própria estrutura, admitem uma realização progressiva e a rigor amplíssima ${ }^{26}$. É preciso então esclarecer em que medida, de fato, a Constituição vincula juridicamente a definição das políticas públicas e, assim, estabelecer os parâmetros de controle que poderão ser utilizados. Pois bem: nesse contexto, é possível imaginar ao menos três tipos diferentes de parâmetros.

\section{Em primeiro lugar, pode-se imaginar uma categoria de parâmetros puramente} objetivos, relacionados com a quantidade de recursos, em termos absolutos ou relativos, que deverá ser aplicada em políticas públicas destinadas a realizar determinadas finalidades constitucionais. A Constituição de 1988, como se sabe, já emprega esse tipo de critério sob variadas formas. Vale destacar três dessas hipótesed:

(i) o art. 212 dispõe que: "A União aplicará, anualmente, nunca menos de" dezoito, e os Estados, o Distrito Federal e os Municípios vinte e cinco por

\footnotetext{
26 Daí visualizar-se nos princípios uma área nuclear e uma área não nuclear. como dois círculos concêntricos. O círculo interior corresponderá a um núcleo de efeitos mínimos que se tornam determinados na medida em que decorrem de forma consensual do sentido elementar do princípio. O espaço intermediário entre o círculo interno e o externo (a coroa circular) será o espaço de expansão do princípio reservado à deliberação democrática; esta é que definirá o sentido, dentre os vários possíveis em uma sociedade pluralista, a ser atribuído ao princípio a partir de seu núcleo. Sobre o tema, v. BARCELLOS, Ana Paula de. A eficácia jurídica dos princípios constitucionais: O princípio da dignidade da pessoa humana, 2002.
} 
cento, no mínimo, da receita resultante de impostos, compreendida a proveniente de transferências, na manutenção e desenvolvimento do ensino";

(ii)o art. $198, \S 2^{\circ}$ dispõe que " $\S 2^{\circ} \mathrm{A}$ União, os Estados, o Distrito Federal $e$ os Municípios aplicarão, anualmente, em ações e serviços públicos de saúde recursos mínimos derivados da aplicação de percentuais calculados sobre: I - no caso da União, na forma definida nos termos da lei complementar prevista no $\$ 3^{\circ}$; II - no caso dos Estados e do Distrito Federal. o produto da arrecadação dos impostos a que se refere o art. 155 e dos recursos de que tratam os arts. 157 e 159, inciso l, alinea a. e inciso II. deduzidas as parcelas que forem transferidas aos respectivos Municipios; III - no caso dos Municípios e do Distrito Federal, o produto da arrecadação dos impostos a que se refere o art. 156 e dos recursos de que tratam os arts. 158 e 159, inciso 1 , alinea b e $\S 3^{\circ "} e$

(iii) a receita obtida pelas contribuições sociais previstas no art. $195^{27}$ deve ser investida no custeio da seguridade social, cujo objetivo é assegurar, nos termos dos arts. 194 e 195, direitos relativos à saúde, à educação e à assistência social.

Essa primeira modalidade de parâmetro é, sem dúvida, a mais simples e objetiva e de emprego mais fácil. Do ponto de vista da sua utilização, bastam duas operações: (i) apurar a quanto correspondem os percentuais referidos pela Constituição em

27 CF/88: "Art. 195. A seguridade social será financiada por toda a sociedade, de forma direta e indireta, nos termos da lei, mediante recursos provenientes dos orçamentos da União, dos Estados, do Distrito Federal e dos Municípios, e das seguintes contribuições sociais: (...)". MARTINS, Marcelo Guerra. Impostos e contribuiçōes federais, 2004, lista as seguintes contribuiçōes sociais, atualmente existentes: (i) do empregador, da empresa e da entidade a ela equiparada na forma da lei, incidentes sobre a folha de salários e demais rendimentos do trabalho pagos ou creditados, a qualquer título, à pessoa física que the preste serviço, mesmo sem vínculo empregatício; (ii) contribuição ao seguro de acidentes de trabalho (SAT); (iii) contribuição do empregador doméstico; (iv) contribuição do empregador, da empresa e da entidade a ela equiparada na forma da lei, incidentes sobre receita ou faturamento: Contribuição sobre o faturamento (CONFINS): ( $v$ ) contribuição ao programa de integração social (PIS); (vi) contribuição de retenção - Tomadores de mão-de-obra: (vii) contribuição de retenção - Cooperativas de trabalho; (viii) contribuição dos clubes de futebol profissional: (ix) contribuição da "agroindústria"; (x) contribuição do empregador, da empresa e da entidade a ela equiparada na forma da lei, incidentes sobre o lucro (CSSL); (xi) contribuição do trabalhador e dos demais e dos demais segurados da previdência social; (xii) contribuição do empregado, do empregado doméstico e do trabalhador avulso: (xiii) contribuição do segurado contribuinte individual e do facultativo: (xiv) contribuição do empregador rural pessoa física e a do segurado especial; ( $x v$ ) contribuição dos concursos prognósticos; $e$ ( $x$ vi) contribuiçòes instituídas dentro da competência residual da União Federal para legislar: Contribuição provisória sobre movimentação ou transmissão de valores e de créditos e direitos de natureza financeira (CPMF). No site do Ministério da Previdência e Assistência Social (www.mpas.gov.bi) é possivel ter acesso a uma lista completa das contribuições com as alíquotas e as bases de cálculo aplicáveis. 
matéria de saúde e educação, considerando a arrecadação dos impostos referidos nos dispositivos e o valor total da receita gerada pelas contribuições: e (ii) verificar se tais recursos estão efetivamente sendo investidos em políticas públicas vinculadas aos fins constitucionais referidos acima. É certo que duas outras ordens de dificuldades precisarão ser enfrentadas, mesmo para a aplicação de parâmetros tão simples como os que se acaba de descrever.

Em primeiro lugar, será preciso ter acesso a informações tanto no que diz respeito aos valores arrecadados pelo Estado, quanto no que toca à aplicação real desses recursos. Em segundo lugar, e este é um ponto juridicamente sensível, uma vez que se verifique o descumprimento do parâmetro constitucional, é preciso definir que consequiências podem ser atribuídas a esse fato, seja para punir o responsável pelo ilícito constitucional, para impedir que o ato por ele praticado produza efeitos. ou ainda para produzir o resultado desejado pela Constituição. Essas duas questões - a necessidade de informação e os instrumentos de controle - serão examinados adiante, em tópicos próprios.

Um segundo parâmetro de controle que se pode construir a partir do texto constitucional diz respeito ao resultado final esperado da atuação estatal. Trata-se de identificar que bens mínimos devem ser afinal ofertados pelo Estado no que diz respeito à promoção dos direitos fundamentais e da dignidade humana. A construção desses parâmetros envolve um trabalho hermenêutico que consiste em extrair das disposições constitucionais efeitos específicos, que possam ser descritos como metas concretas a serem atingidas em caráter prioritário pela ação do Poder Público.

Assim, e.g., é possível afirmar que o Estado brasileiro está obrigado a, prioritariamente, oferecer educação fundamental a toda a população. sem qualquer custo para o estudante (CF, art. 208, $\left.\mathrm{I}^{28}\right)$. Os recursos públicos disponíveis, portanto, devem ser investidos em políticas capazes de produzir esse resultado até que ele seja efetivamente atingido. Enquanto essa meta concreta não houver sido alcançada, outras políticas públicas não prioritárias do ponto de vista constitucional terão de aguardar ${ }^{29}$.

Note-se que o parâmetro objetivo descrito acima convive com este segundo, que se ocupa do resultado final da atuação estatal. Prosseguindo no exemplo da educação, é certo que todos os recursos previstos nos arts. $195,198, \S 2^{\circ}$ e 212 da Constituição terão de ser investidos em serviços de educação pelos diferentes entes federativos. Se esse investimento, porém, não for suficiente para produzir o resultado esperado - a oferta de educação fundamental gratuita para toda a população -.

28 “Art. 208. O dever do Estado com a educação será efetivado mediante a garantia de: I — ensino fundamental, obrigatório e gratuito, assegurada, inclusive, sua oferta gratuita para todos os que a ele não tiveram acesso na idade própria."

29 O exemplo, é claro, simplifica a realidade para ilustrar o ponto, pois, na verdade, algumas metas são igualmente prioritárias do ponto de vista constitucional e deverão ser perseguidas concomitantemente. 
outros recursos além desse mínimo terão de ser aplicados em políticas públicas até que a meta seja alcançada. Por outro lado, se o resultado em questão for atingido com um investimento menor do que o mínimo previsto constitucionalmente, o restante dos recursos continuará a ser aplicado em educação, agora na realização de outras metas previstas pelo texto constitucional, como, e.g., a progressiva universalização do ensino médio ${ }^{30}$ etc.

O exemplo da educação foi utilizado propositalmente por sua relativa simplicidade. Em outras áreas, como saúde e assistência social, por exemplo, a definição de metas concretas que decorrem da Constituição e são exigíveis do Poder Público envolvem complexidades maiores e, por isso mesmo, tais temas devem ser enfrentados de forma específica. Que espécie de prestação de saúde deve ser obrigatoriamente oferecida pelo Estado à população como um todo? Não será possível afirmar, evidentemente, que todas as prestações existentes estão nesse rol, sob pena de esvaziar totalmente o espaço de escolha política na matéria e conduzir os recursos públicos a uma possível exaustão, considerando a progressiva sofisticação e 0 incremento do custo dos serviços de saúde. Isso não significa. de outra parte. que não haja um conjunto de prestações mínimas que deva ser oferecido pelo Estado independentemente do grupo político no poder.

Uma vez definidas essas metas concretas, que devem ser prioritariamente perseguidas pelo Poder Público, a aplicação do parâmetro de controle também não envolve, em si mesmo, maiores dificuldades lógicas. Trata-se de verificar se o resultado final da atividade do Estado em cada uma das áreas está efetivamente se produzindo. Se a resposta a essa indagação for negativa, os recursos disponíveis deverão ser obrigatoriamente aplicados em políticas públicas vinculadas a essa finalidade constitucional, de modo que outros gastos, não prioritários, devem esperar. As mesmas questões relacionadas com a informação sobre receitas e despesas públicas e com as consequiências a atribuir na hipótese de descumprimento do parâmetro constitucional se colocam aqui e serão examinadas adiante.

Um terceiro parâmetro de que se pode cogitar, mais complexo, envolve o controle da própria definição das políticas públicas a serem implementadas. Isto é: dos meios escolhidos pelo Poder Público para realizar as metas constitucionais. Essa modalidade de parâmetro poderá ser utilizada em conjunto com as anteriores, que envolvem, como se viu, não o processo para alcançar as metas constitucionais. mas a definição das próprias metas.

A escolha das políticas públicas a serem implementadas ou, em outros termos, dos meios através dos quais as finalidades constitucionais podem ser alcançadas é atividade tipicamente reservada pela Constituição à definição político-majoritária. A Constituição fixa, de forma vinculante, fins ou metas que devem ser obrigatoriamente cumpridos pelo Poder Público - sobre isso se tratou nos parâmetros anteriores

30 “Art. 208. O dever do Estado com a educação será efetivado mediante a garantia de:

II - progressiva universalização do ensino médio gratuito." 
-. mas como atingir esses fins cabe ao Poder Público definir ${ }^{3 !}$. De que parâmetro de controle se poderia falar aqui então? Se na construção de qualquer parâmetro de controle é preciso especial cuidado para não invadir, com o Direito, o espaço próprio da política, mais ainda quando esse parâmetro envolva a limitação do espectro de escolha dos poderes constituídos em matéria de políticas públicas.

Nada obstante o que se acaba de afirmar, e ainda assim, é possível conceber parâmetros de controle nesse particular para o fim de eliminar das possibilidades de escolha à disposição das autoridades públicas os meios comprovadamente ineficientes para a realização das metas constitucionais. $O$ objetivo do parâmetro é assegurar uma eficiência mínima ${ }^{32}$ às ações estatais e seu fundamento decorre de tudo o que já se expôs sobre a vinculação do Estado às metas constitucionais e sobre as escolhas públicas em um Estado democrático e republicano.

$\mathrm{Na}$ realidade, a vinculação jurídica dos fins constitucionais não se reduz a um mero pretexto retórico. Ou seja: a capacidade da autoridade pública de associar suas políticas públicas aos fins constitucionais por meio de argumentação retórica não satisfaz a imposição constitucional. As políticas públicas têm de contribuir com uma eficiência mínima para a realização das metas estabelecidas na Constituição; caso contrário, não apenas se estará fraudando as disposições constitucionais, como também desperdiçando recursos públicos que, como já se sublinhou, são sempre escassos em face das necessidades existentes.

É bem de ver que, salvo diante de situações extremas, o intérprete jurídico dificilmente terá condições de avaliar, sozinho, se a política pública adotada pela autoridade é minimamente eficiente. Neste ponto, será indispensável a comunicação do Direito com outros ramos do conhecimento, que poderão fornecer essa espécie de informação ao jurista com consistência científica. Não se trata, repita-se, de julgar entre eficiências maiores ou menores, nem de substituir a avaliação política da autoridade democraticamente eleita pela do juiz, mas apenas de eliminar as hipóteses de ineficiência comprovada. Assim, se houver consenso técnico-científico de que o meio escolhido pelo Poder Público é ineficiente, ele será também juridicamente inválido, pois não se poderá considerá-lo um meio legitimamente destinado a realizar o fim constitucional.

31 BARROSO, Luís Roberto. O direito constitucional e a efetividade de suas normas, 2002, p. 118.

32 CF/88: "Art. 37. A administração pública direta e indireta de qualquer dos Poderes da União, dos Estados, do Distrito Federal e dos Municípios obedecerá aos princípios de legalidade, impessoalidade, moralidade, publicidade e eficiência (...).". V. DI PIETRO. Maria Sylvia Zanella. Direito administrativo, 2002, p. 83; Á VILA, Humberto. Moralidade, razoabilidade e ficiência na atividade administrativa, Revista Brasileira de Direito Público $n^{\circ} 1,2003, p p .105$ a 133; e MARTINS JÚNIOR, Wallace Paiva. A discricionariedade administrativa à luz do princípio da eficiência, Revista dos Tribunais $n^{\circ} 789,2001$, p. 87-8: "O princípio da eficiência toi introduzido para reordenação das atividades administrativas e. também, para servir como parâmetro (ou baliza) da juridicidade do exercício da competência administrativa (discricionária ou vinculada). (...) O atendimento das bases da moderna Administração Pública exige - além da conformidade da atuação administrativa com a legalidade - conveniência, oportunidade e eficiência (...)* 


\section{III.2. Garantia de acesso à informação}

Uma vez que os parâmetros tenham sido construídos, sua aplicação efetiva depende de dispor-se de informação acerca (i) dos recursos públicos disponíveis; (ii) da previsão orçamentária; e (iii) da execução orçamentária. Esse poderia ser um tema de importância menor se a realidade brasileira não provasse o oposto em muitos aspectos $^{33}$.

No campo das receitas públicas, diversos orçamentos não distinguem a arrecadação prevista por tributos. Na mesma linha, os relatórios acerca da arrecadação efetivamente verificada, quando disponíveis ao público, nem sempre discriminam as receitas por espécie tributária. Ora, se os parâmetros de controle objetivos já previstos no texto constitucional, e.g., para investimentos mínimos em saúde e educação devem ser calculados com base em um combinado de receitas oriundas de tributos específicos, a ignorância acerca de tais informações dificulta a aplicação do parâmetro.

No campo das despesas a dificuldade é ainda maior, tanto no que diz respeito às previsões orçamentárias, quanto no que toca à execução do orçamento, isto é, às despesas de fato realizadas. Diversos orçamentos, de diferentes níveis federativos, aprovam apenas uma verba geral para despesas, sem especificação; outros veiculam uma listagem genérica de temas, sem que seja possível identificar minimamente quais as políticas públicas que se deseja implementar.

Os relatórios de execução orçamentária nem sempre existem e, em geral, são pouco informativos. As despesas estão associadas a rubricas bastante amplas, como, e.g., "Encargos Especiais", ou aos órgãos públicos (e.g., Ministérios e Secretarias), sem que se possa saber ao certo o que foi investido na atividade fim do órgão, como saúde e educação, e o que foi gasto com outras despesas, como publicidade do órgão, remuneração de servidores, verbas de representação etc.. No caso da União, como se sabe, existem bancos de dados que registram todas as despesas do Executivo de forma individualizada (dos quais o SIAFI é o principal), mas seu acesso é restrito a deputados e senadores ${ }^{34}$. Não se tem de notícia de que os demais entes federativos contem com estrutura semelhante.

33 As informações contidas nos parágrafos seguintes foram obtidas por meio de levantamento e pesquisa na legislação orçamentária e nos dados disponíveis ao público relativamente à previsão orçamentária, à arrecadação e à execução orçamentária da União, do Estado do Rio de Janeiro e do Município do Rio de Janeiro nos últimos quatro anos (2000 a 2004). Trata-se, é certo, de uma pequena amostra da realidade brasileira, mas ainda assim bastante significativa.

34 Em 2004, o Presidente da República vetou da Lei de Diretrizes Orçamentárias (Lei $n^{\circ} 10.934$. de 11.08.2004) a previsão, tradicional, que confere aos parlamentares o acesso a tais sistemas de informações (tratava-se do art. $100 \mathrm{da}$ lei). Após grande reação dos parlamentares, o dispositivo foi reintroduzido pela Lei $n^{\circ} 11.086$, de 31.12.2004. Este é o texto do artigo: "Para fins de apreciação da proposta orçamentária, do acompanhamento e da fiscalização orçamentária a que se refere o art. $166, \S 1^{\circ}$, inciso II, da Constituição, será assegurado ao órgão responsável o acesso irrestrito, para fins de consulta, aos seguintes sistemas, bem como o recebimento de seus dados. em meio digital:

I - Sistema Integrado de Administração Financeira do Governo Federal - Siafi; 
A dificuldade geral de obter informação sobre o tema aqui em estudo não é um problema apenas de caráter pragmático que, em tese, poderia ser superado mediante um amplo esforço de pesquisa junto aos Legislativos dos três níveis federativos, aos órgãos competentes da Administração Pública e aos Tribunais de Contas. Trata-se também de um problema jurídico, já que o dever de prestar contas é um dever de natureza jurídica que, como tal, pode ser coativamente exigido ${ }^{35}$. Salvo situações excepcionais, e.g., de despesas relacionadas com a segurança nacional, cujo sigilo seja constitucionalmente justificado, os cidadãos têm o direito subjetivo de dispor de informação sobre a receita pública existente e as despesas planejadas e realizadas pelos órgãos governamentais. De forma muito simples, o cidadão tem o direito de saber de quanto dinheiro o Estado dispõe e em que ele está sendo gasto.

E vale aqui notar um ponto importante. O direito à informação de que se acaba de tratar sumariamente não está ligado apenas - e a rigor sequer primariamente à possibilidade de controle jurídico das escolhas do Estado em matéria de políticas públicas. Seu vínculo direto é com a prerrogativa assegurada ao povo, em um Estado democrático, de exercer controle político sobre a atuação do Estado. seja na via periódica das eleições, seja na via contínua de protestos e pressões sobre os representantes eleitos. Em suma: a sonegação dos dados sobre receitas e despesas públicas inviabiliza os controles jurídico e político e nessa medida poderá exigir soluções jurídicas que assegurem, coativamente se necessário, o acesso à informação.

\section{III.3. Elaboração de instrumentos de controle}

O controle jurídico-constitucional das políticas públicas depende da construção dos parâmetros que serão utilizados, de informação acerca das receitas e despesas e, por fim, de instrumentos de controle. Com efeito, uma vez que os parâmetros sejam fixados e se verifique, em determinado momento e circunstância, que eles não foram observados, que consequiências a ordem jurídica atribuirá a esse fato?

Il - Sistema Integrado de Dados Orçamentários - Sidor;

III - Sistema de Análise Gerencial de Arrecadação - Angela, bem como as estatísticas de dados agregados relativos às informações constantes das declarações de imposto de renda das pessoas físicas e jurídicas, respeitado o sigilo fiscal do contribuinte;

IV - Sistemas de Gerenciamento da Receita e Despesa da Previdência Social:

V - Sistema de Informações Gerenciais e de Planejamento do Plano Plurianual - Sigplan:

VI - Sistema de Informação das Estatais - Siest; e

VII - Sistema Integrado de Administração de Serviços Gerais - Siasg."

35 CF/88: "Art. 70. A fiscalização contábil, financeira, orçamentária, operacional e patrimonial da União e das entidades da administração direta e indireta, quanto à legalidade, legitimidade, economicidade, aplicação das subvenções e renúncia de receitas, será exercida pelo Congresso Nacional. mediante controle externo, e pelo sistema de controle interno de cada Poder.

Parágrafo único. Prestará contas qualquer pessoa física ou jurídica, pública ou privada, que utilize, arrecade, guarde, gerencie ou administre dinheiros, bens e valores públicos ou pelos quais a União responda, ou que, em nome desta, assuma obrigações de natureza pecuniária." 
Se os parâmetros em questão são, na realidade, regras construídas a partir do texto constitucional, isto é, regras jurídicas dotadas de superioridade hierárquica e centralidade no sistema jurídico, sua violação deverá acarretar consequêencias jurídicas, seja para punir o infrator, para impedir que o ato praticado em descumprimento da regra produza efeitos, ou ainda para impor a observância da regra. Ou seja: em primeiro lugar, é possível imaginar algum tipo de penalidade aplicável ao responsável uma vez que se verifique o não oferecimento, e.g., de educação fundamental ou de atendimento médico básico a toda a população. Na segunda linha, é possível conceber que o Estado seja proibido de gastar com, e.g., publicidade governamental, até que as metas prioritárias estabelecidas pela Constituição sejam alcançadas. Em terceiro lugar, pode-se cogitar de o próprio Judiciário ser autorizado a impor aos demais Poderes Públicos o investimento nas metas constitucionais.

É fácil perceber que há uma gradação nesses três grupos de conseqüências possíveis: punição, ineficácia do ato que viola a regra e possibilidade de, substitutivamente ao agente competente, produzir coativamente o que foi determinado pela Constituição. A última possibilidade é. sem dúvida, a que de forma mais efetiva realiza os efeitos pretendidos pela regra constitucional construída (os parâmetros), mas é também, por outro lado, a que mais interfere com as atribuições próprias do espaço político. As duas outras possibilidades impõem apenas indiretamente a realização das pretensões constitucionais, preservando o espaço de escolha da instância política. O equilíbrio possível entre esses dois elementos deve ser levado em conta na construção desses instrumentos de controle.

Dentro de cada uma dessas três categorias sugeridas acima é possível visualizar uma série de possibilidades diversas, algumas delas já indicadas pelo texto constitucional. Assim, nos termos do artigo 208 , $\S 2^{036}$, o não oferecimento de educação fundamental nos termos previstos na Constituição desencadeia a responsabilidade pessoal da autoridade competente. Ainda no campo da incidência de penalidades, é possível cogitar a responsabilidade política, na figura do crime de responsabilidade, da autoridade que atenta contra a Constituição e, especialmente, contra o "exercício dos direitos políticos, individuais e sociais" ( $\mathrm{CF}$, art. $85^{37}$ ).

O não investimento dos mínimos exigidos em educação e saúde autoriza, como se sabe, a intervenção federal nos Estados e dos Estados nos Municípios (CF, arts. 34 , VII, e, e 35, III $^{38}$ ), cabendo ao interventor levar o ente federativo a obedecer à

$36 \mathrm{CF} / 88$ : "Art. 208. $\$ 2^{\circ}$. O não-oferecimento do ensino obrigatório pelo Poder Público. ou sua oferta irregular, importa responsabilidade da autoridade competente."

37 CF/88: " Art. 85. São crimes de responsabilidade os atos do Presidente da República que atentem contra a Constituição Federal e, especialmente, contra: (...) III - o exercício dos direitos políticos. individuais e sociais;"

Lei 1.079/50: "Art. $7^{\circ}$. São crimes de responsabilidade contra o livre exercício dos direitos políticos, individuais e sociais: (...) 9 - violar patentemente qualquer direito ou garantia individual constante do art. 141 e bem assim os direitos sociais assegurados no artigo 157 da Constituiçāo:

10 - tomar ou autorizar durante o estado de sítio, medidas de repressão que excedam os limites estabelecidos na Constituição."

38 CF/88: "Art. 34. A União não intervirá nos Estados nem no Distrito Federal. exceto para: 
Constituição. A legislação infraconstitucional já prevê alguns instrumentos de controle, aplicáveis em determinadas circunstâncias, que podem servir como ponto de partida para reflexão nesse particular - em especial a Lei Complementar $n^{\circ} 101 / 00$ (responsabilidade fiscal) e a Lei $n^{\circ} 8.429 / 92$ (improbidade administrativa). Talvez esse seja também o momento de repensar a teoria jurídica que prevalece até hoje no Brasil acerca do orçamento, sobretudo de seu papel na definição das políticas públicas e de seus efeitos.

A construção fundamentada de instrumentos de controle será provavelmente o ponto mais complexo e sensível dos três que se acaba de expor. Por isso mesmo, a reflexão sobre ele é urgente e exige especial atenção da doutrina, sem a soberba de pretensos reis filósofos, mas com a missão de transformar o discurso da juridicidade. superioridade e centralidade das normas constitucionais em geral. e dos direitos fundamentais em particular, em técnica aplicável no cotidiano da interpretação e aplicação do direito. E uma vez que o discurso se transforme em técnica, a técnica poderá ser transformar em diferença real para as pessoas que vivem em um Estado de direito constitucional.

\section{Conclusões}

É possível compendiar as principais idéias desenvolvidas no texto por meio das seguintes proposições objetivas:

1. A expressão "neoconstitucionalismo" designa o estado do constitucionalismo contemporâneo, que apresenta características metodológico-formais e materiais. O constitucionalismo atual opera sobre três premissas metodológico-formais fundamentais (a normatividade. a superioridade e a centralidade da Constituição) e pretende concretizá-las elaborando técnicas jurídicas que possam ser utilizadas no dia-a-dia da aplicação do direito. Quanto às características materiais, ao menos dois elementos merecem nota: (i) a incorporação explícita de valores e opções políticas nos textos constitucionais relacionados com a dignidade humana e os direitos fundamentais; e (ii) a expansão de conflitos entre as opções normativas e filosóficas existentes dentro do próprio sistema constitucional.

2. A Constituição estabelece como um de seus fins essenciais a promoção dos direitos fundamentais. As políticas públicas constituem o meio pelo qual os fins constitucionais podem ser realizados de forma sistemática e abrangente. mas envolvem gasto de dinheiro público. Como se sabe, os recursos públicos são limitados e

VII - assegurar a observância dos seguintes princípios constitucionais: (...) e) aplicação do mínimo exigido da receita resultante de impostos estaduais, compreendida a proveniente de transferências, na manutenção e desenvolvimento do ensino e nas ações e serviços públicos de saúde."

$\mathrm{CF} / 88$ : "Art. 35. O Estado não intervirá em seus Municípios. nem a União nos Municípios localizados em Território Federal, exceto quando: (...) III - não tiver sido aplicado o mínimo exigido da receita municipal na manutenção e desenvolvimento do ensino e nas ações e serviços públicos de saúde:" 
é preciso fazer opções. As escolhas em matéria de gastos e políticas públicas não constituem um tema integralmente reservado à deliberação política; ao contrário, o ponto recebe importante incidência de normas jurídicas constitucionais.

3. A construção do controle das políticas públicas depende do desenvolvimento teórico de três temas: (i) a identificação dos parâmetros de controle: (ii) a garantia de acesso à informação; e (iii) a elaboração dos instrumentos de controle. Assim, em primeiro lugar, é preciso definir, a partir das disposições constitucionais que tratam da dignidade humana e dos direitos fundamentais, o que o Poder Público está efetiva e especificamente obrigado a fazer em caráter prioritário; isto é, trata-se de construir parâmetros constitucionais que viabilizem o controle. O segundo tema diz respeito à obtenção de informação acerca dos recursos públicos disponíveis, da previsão orçamentária e da execução orçamentária. O terceiro tema, por sua vez, envolve o desenvolvimento de consequiências jurídicas a serem aplicadas na hipótese de violação dos parâmetros construídos, seja para impor sua observância, para punir o infrator ou para impedir que atos praticados em violação dos parâmetros produzam efeitos. 


\section{Direitos Reais e Autonomia da Vontade}

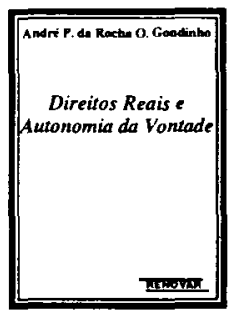

André P. da Rocha O. Gondinho

Ref. 0298

Brochura

167 págs.

Form. $13,5 \times 21$

2001

ISBN 85-7147-231-9

0 autor entrenta temas pouco explorados por nossa doutrina: o princípio da tipicidade dos direitos reais e toda a problemática resultante da limitação legal dos direitos reais no Brasil. Sua proposta tem por objetivo apurar a rigidez do princípio da tipicidade dos direitos reais, fixando, para tal empreitada, os contornos dogmáticos do princípio e a possibilidade da autonomia da vontade moldar situações reais, ou com eficácia real, merecedoras de tutela jurídica.

\section{Divórcio e Separação Judicial \\ Doutrina - Legislaçāo - Jurisprudência - Direito Comparado}

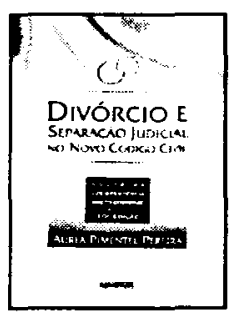
Aurea Pimentel Pereira
Ref. 0013
Brochura
270 págs.
Form. $14 \times 21$
$2004 / 11^{\mathrm{a}} \mathrm{ed}$.
ISBN $85-7147-460-5$

É de grande utilidade para os profissionais e interessados em Direito de Família. A autora, em linguagem clara, comenta, artigo por artigo, a Lei do Divórcio, apontando suas alterações decorrentes da Constituição de 1988. Os aspectos controvertidos são abordados, com especial cuidado, unindo a longa experiência da autora, que muitas vezes diverge de outros comentadores, mas justifica seu entendimento e cita doutrina e jurisprudência.

\section{Do Pátrio Poder à Autoridade Parental Repensando Fundamentos Juridicos da Relaçăo entre Pais e Filhos}

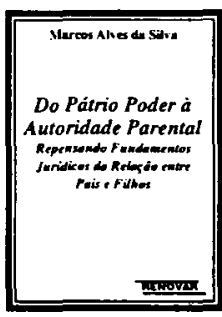

\author{
Marcos Alves da Silva \\ Ref. 0395 \\ Brochura \\ 244 págs. \\ Form. $13,5 \times 21$ \\ 2002 \\ ISBN 85-7147-848-1
}

Compreende a migração operada do CC à Constituição, captando, à luz da teoria crítica do Direito Civil, o sistema clássico originário do CC brasileiro e o Direito Constitucional da Família. Para tratar do percurso que inicia com o pátrio poder e que alcança a autoridade parental, compreendendo o Código de 1916 e a nova denominação ("poder familiar") do CC de 2002, apreendeu 0 autor um campo de saber que rompe as fronteiras tradicionais do público e do privado.

\section{Elementos de Responsabilidade Civil}

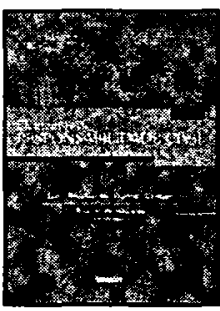
Luiz Roldāo de Freitas Gomes

Ref. 0252

Encadernado

446 págs.

Form. $16 \times 23$

2000

ISBN 85-7147-165-7

De caráter altamente didático, discorre sobre o conceito da responsabilidade civil, em cotejo com a penal, sobre sua classificaçāo, controvertida, em contratual e extracontratual, e analisa a responsabilidade fundada na culpa e no risco. Perpassa pelos fundamentos de uma e outra, procurando demonstrar que ambas hão de conviver, respondendo a diversas exigências. 